\title{
Understanding the Processus Vaginalis! The Abdomino Scrotal Hydrocoele
}

\author{
Entendiendo el Proceso Vaginal! El Hidrocele Abdomino-Escrotal
}

Arcot Rekha \& A. Ravi

REKHA, A. \& RAVI, A. Understanding the processus vaginalis! The abdomino scrotal hydrocoele. Int. J. Morphol., 30(1):61-63, 2012.

SUMMARY: A knowledge of the embryology and descent of the testes is essential for all clinicians. Congenital hydrocoele, though an embryologic anomaly can present in adulthood. A abdomino scrotal hydrocole must be considered when a mass in the lower abdomen co exists with a scrotal hydrocoele.

KEY WORDS: Embryologic anomaly; Processus vaginalis; Patent processus vaginalis; Abdomino scrotal hydrocoele.

\section{INTRODUCTION}

The testes develop from the genital ridge in the lumbar region in the seventh week of intra uterine life. They begin their descent towards the scrotum (in the twenty eighth week of intra uterine life), and a fold of peritoneum, the processus vaginalis (PV) paves the way with the gubernaculum as the rudder. Failure of obliteration of the $\mathrm{PV}$, gives rise to the variants of the congenital hydrocoele

\section{CASE REPORT}

A 30-year-old man sought medical attention with complaints of a fullness in the lower abdomen associated with discomfort. Examination revealed a rounded mass in the right lower abdomen $4 ¥ 4 \mathrm{~cm}$ in size, and the lower border was not well appreciated. The patient also had a swelling in the right scrotum that was soft cystic, fluctuant and trans illuminant (Fig. 1) (a vaginal hydrocoele). There was no obvious cross fluctuation between the two. Baseline laboratory values were normal and ultra sound showed a cystic mass in the right lower abdomen and the scrotal ultrasound showed a hydrocoele. Computerized tomography (CT) showed a cystic mass in the region of the superficial ring in close proximity to the spermatic cord (Fig. 2). Traction on the right testis showed some mobility of the mass.

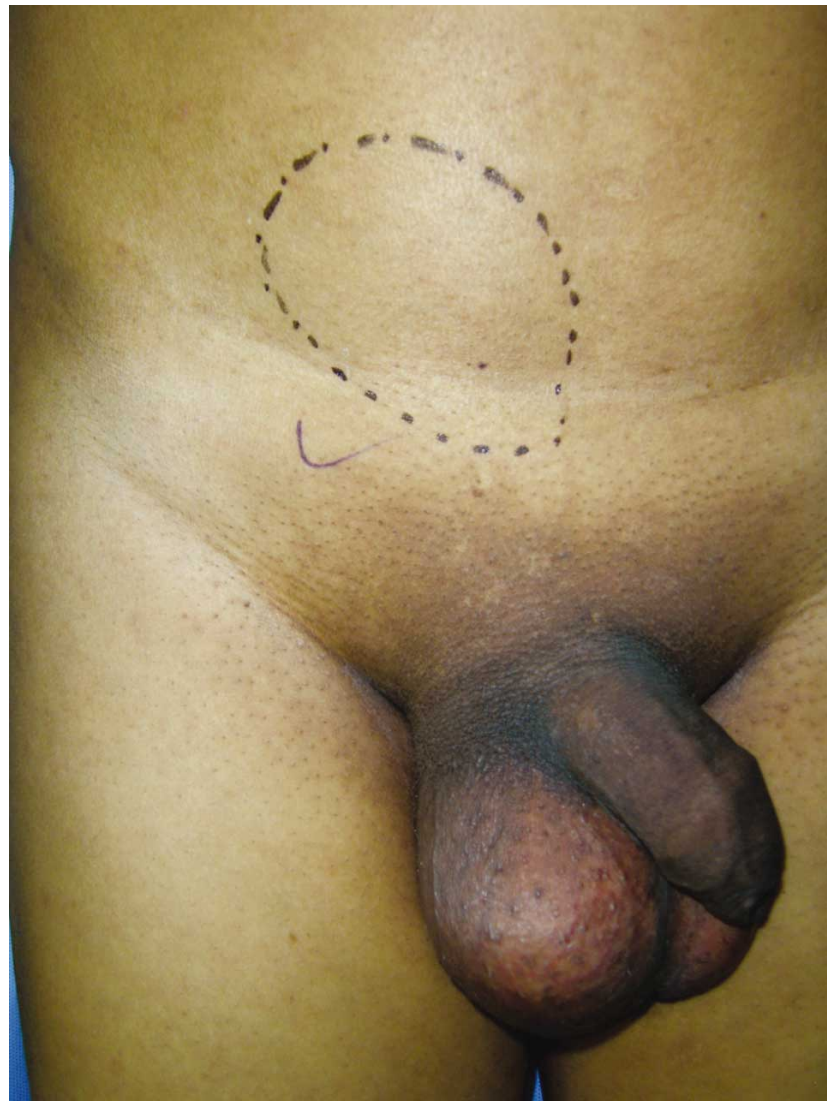

Fig. 1. A vaginal hydrocoele in the patient. 


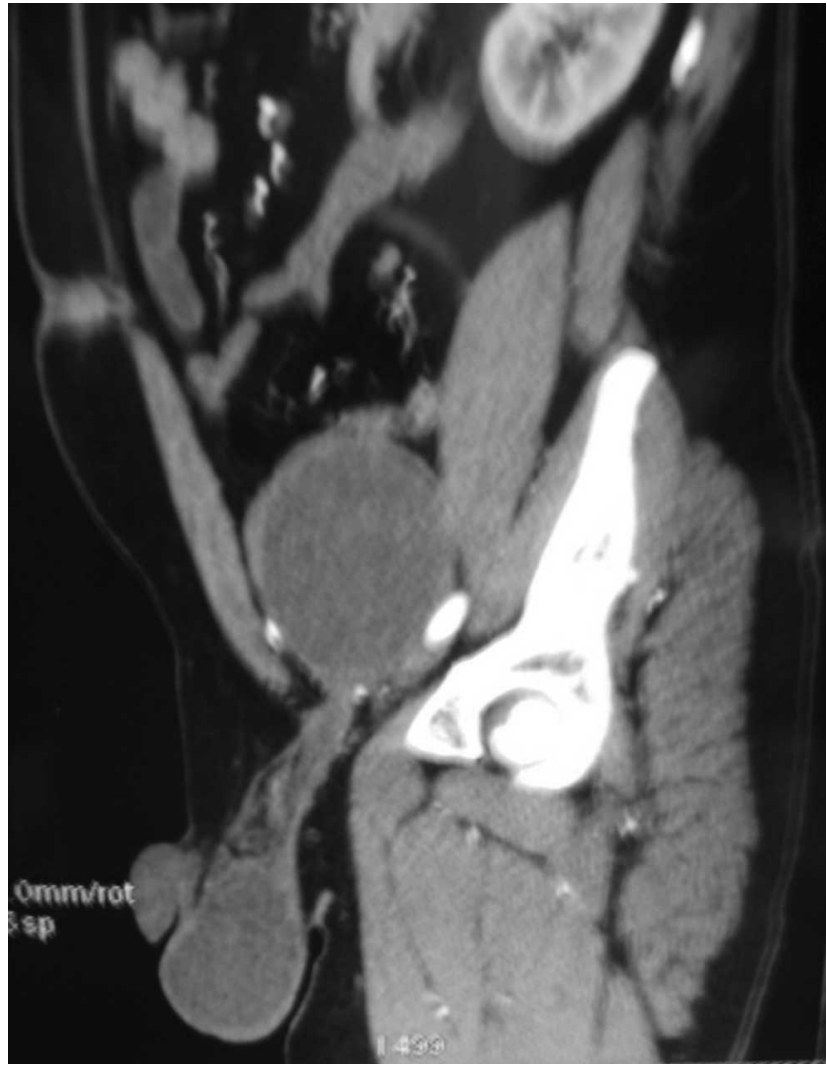

Fig. 2. CT showed a cystic mass in the region of the superficial ring in close proximity to the spermatic cord.

At surgery, the abdominal mass was found to be arising from the spermatic cord (an encysted hydrocoele), which on very careful dissection showed a fine channel extending inferiorly to the vaginal hydrocoele (Fig. 3). The abdomino scrotal hydrocele was excised and the PV was ligated.

\section{DISCUSSION}

A patent processus vaginalis (PPV) has been estimated to be present in $80-95 \%$ of all male newborns, declining to $60 \%$ at one year of age, $40 \%$ at two years, and $15-37 \%$ thereafter. It represents a natural communication between the peritoneum and scrotum through which bowel or peritoneal fluid may descend. The testes develop from the genital ridge and make their way aided by the PV into the scrotum (Benjamin, 2002). During the process of normal testicular descent, the role of numerous mechanical components has been hypothesized, including a normal gubernaculum, epididymis, intra-abdominal pressure, and the innervation of the gubernaculum by the genitofemoral nerve (Belman, 2001). The PV develops within the

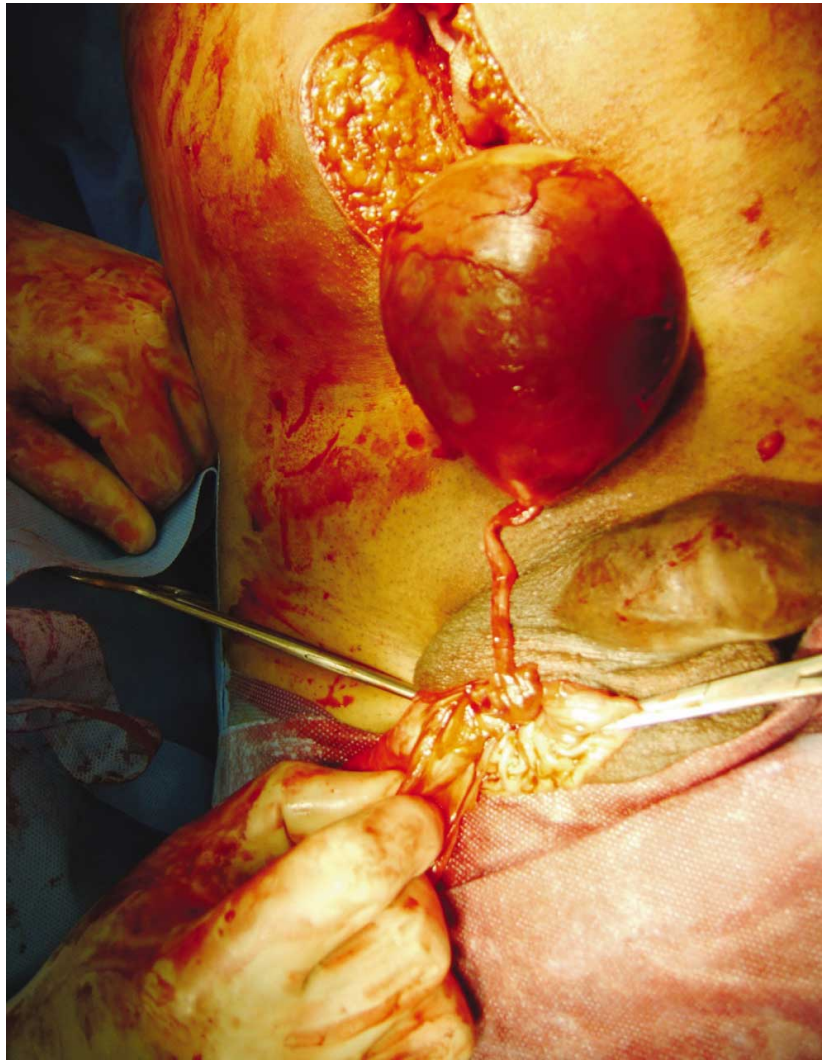

Fig. 3. Surgery of the abdominal mass arising from the spermatic cord.

gubernacular mesenchyma that invades and migrates into the scrotum, and provides a potential space into which the testis descends. The regression of gubernaculum testis and the obliteration of the PV normally occur soon after the testicular descent has been completed (Cozzi et al., 2008). Therefore, both events may occur in response to the same stimuli. This route will also allow the passage of other intraperitoneal fluid including blood, as seen occasionally following splenic rupture, and peritoneal dialysis fluid in renal patients. The $\mathrm{PV}$ obliterates and in the normal adult is a layer over the testis. Collection of fluid between the layers of the tunica vaginalis is called a vaginal hydrocoele.

The other variant of the PPV is a congenital hydrocoele where the communication extends through the deep inguinal ring into the peritoneum. The patient gives a history of the mass that is not apparent on waking up, but appears progressively through the day. A cough impulse is present, but it is not possible to reduce the swelling due to "the inverted ink bottle effect".

The infantile variant is where the PV extends up to the deep ring but is not in communication with the peritoneum. In the encysted hydrocoele of the cord a portion 
of the PV, somewhere in the course, traps and retains the fluid. Traction test is typical of this swelling.

The abdomino scrotal hydrocoele is the variant where a fine channel connects the abdominal and the scrotal component. Cross fluctuation is often elicited except when fibrosis obliterates the channel partially (Saharia et al., 1979; Chang et al., 2010; Hisamatsu et al., 2010).

The congenital hydrocoele differs from the hernia in that in the latter, bowel loops or omentum attempt to descend through the defect, while in the former it is only peritoneal fluid. Long standing and large hydrocoeles may be associated with testicular atrophy. Elder also showed that $64 \%$ of epididymides were abnormal when the PV was completely patent, while only $11 \%$ were abnormal when the PV was incompletely patent in boys with hydrocele/hernia or undescended testis (Elder, 1992).

For diagnosis and treatment, a careful history and a methodical clinical examination clinch the diagnosis. CT and sonography are aids in diagnosis (Karmazyn, 2010). Diagnostic laparoscopy is useful in identifying asymptomatic patent processus vaginalis. Treatment consists of surgical excision and ligation, though there are some reports of spontaneous obliteration (Toki et al., 2003). An inguinal approach to ligate the processus vaginalis is the mainstay in treatment (Ho et al., 2010). Laparoscopic ligation is making rapid strides towards becoming the gold standard (Wilson et al., 2008).

REKHA, A. \& RAVI, A. Entendiendo el proceso vaginal! El hidrocele abdomino-escrotal. Int. J. Morphol., 30(1):61-63, 2012.

RESUMEN: El conocimiento de la embriología y el descenso de los testículos es esencial para todos los clínicos. El hidrocele congénito, aunque es una anomalía embriológica se puede presentar en la edad adulta. Un hidrocele abdomino-escrotal debe ser considerado cuando una masa en la parte inferior del abdomen co existe con un hidrocele testicular.

PALABRAS CLAVE: Anomalía embriológica; Proceso vaginal; Proceso vaginal latente; Hidrocele abdomino escrotal.

\section{REFERENCES}

Belman, A. B. Abdominoscrotal hydrocele in infancy: a review and presentation of the scrotal approach for correction. J. Urol., $165(1): 225-7,2001$.

Benjamin, K. Scrotal and inguinal masses in the newborn period. Adv. Neonatal Care, 2(3):140-8, 2002.

Cozzi, D. A.; Mele, E.; Ceccanti, S.; Pepino, D.; d'Ambrosio, G. \& Cozzi, F. Infantile abdominoscrotal hydrocele: a not so benign condition. J. Urol., 180(6):2611-5, 2008.

Chang, Y. T.; Lee, J. Y.; Wang, J. Y.; Chiou, C. S. \& Chang, C. C. Hydrocele of the spermatic cord in infants and children: its particular characteristics. Urology, 76(1):82-6, 2010

Elder, J. S. Epididymal anomalies associated with hydrocele/hernia and cryptorchidism: implications regarding testicular descent. J. Urol., 148(2 Pt 2):624-6, 1992.

Hisamatsu, E.; Takagi, S.; Nomi, M. \& Sugita, Y. A case of bilateral abdominoscrotal hydroceles without communication with the peritoneum. Indian J. Urol., 26(1):129-30, 2010.

Ho, C. H.; Yang, S. S. \& Tsai, Y. C. Minilaparoscopic high-ligation with the processus vaginalis undissected and left in situ is a safe, effective, and durable treatment for pediatric hydrocele. Urology, 76(1):134-7, 2010.
Karmazyn, B. Scrotal Ultrasound. Ultrasound Clinics, 5(1):61-74, 2010.

Saharia, P. C.; Bronsther, B. \& Abrams, M. W. Abdominoscrotal hydrocele. Case presentation and review of the literature. J. Pediatr. Surg., 14(6):713-4, 1979.

Toki, A.;Watanabe, Y.; Sasaki, K.; Tani, M.; Ogura, K. \& Wang, Z. $\mathrm{Q}$. Adopt a wait-and-see attitude for patent processus vaginalis in neonates. J. Pediatr. Surg., 38(9):1371-3, 2003.

Wilson, J. M.; Aaronson, D. S.; Schrader, R. \& Baskin, L. S. Hydrocele in the pediatric patient: inguinal or scrotal approach? J. Urol., 180(4 Suppl):1724-8, 2008.

Correspondence to:

Prof. Arcot Rekha

Prof. of Surgery

Sri Ramachandra Medical College

and Reserach Institute,

Chennai-600116

INDIA

Email: rekha_a@yahoo.com

Received: 19-06-2011

Accepted: 02-08-2011 